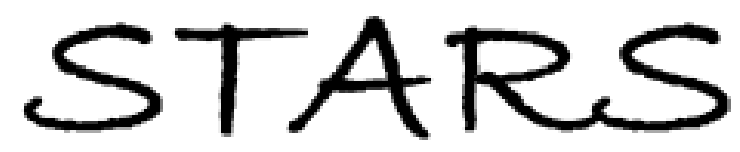

University of Central Florida

STARS

$1-1-1997$

\title{
Polymer waveguides with optimized overlap integral for modal dispersion phase-matching
}

\section{W. Wirges}

S. Yilmaz

W. Brinker

S. Bauer-Gogonea

S. Bauer

See next page for additional authors

Find similar works at: https://stars.library.ucf.edu/facultybib1990

University of Central Florida Libraries http://library.ucf.edu

This Article is brought to you for free and open access by the Faculty Bibliography at STARS. It has been accepted for inclusion in Faculty Bibliography 1990s by an authorized administrator of STARS. For more information, please contactSTARS@ucf.edu.

\section{Recommended Citation}

Wirges, W.; Yilmaz, S.; Brinker, W.; Bauer-Gogonea, S.; Bauer, S.; Jäjer, M.; Stegeman, G. I.; Ahlheim, M.; Stähelin, M.; Zysset, B.; Lehr, F.; Diemeer, M.; and Flipse, M. C., "Polymer waveguides with optimized overlap integral for modal dispersion phase-matching" (1997). Faculty Bibliography 1990s. 2134. https://stars.library.ucf.edu/facultybib1990/2134

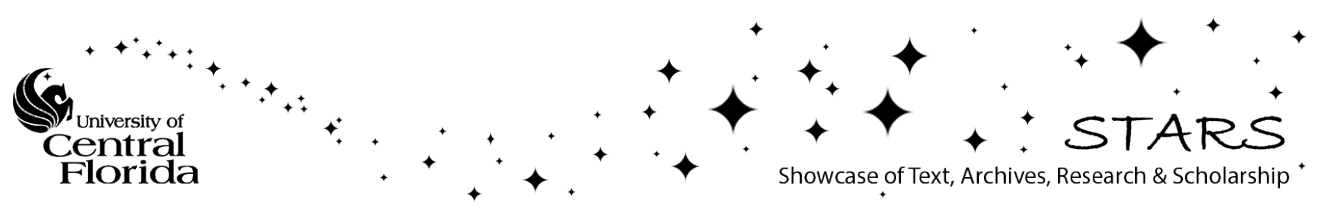


Authors

W. Wirges, S. Yilmaz, W. Brinker, S. Bauer-Gogonea, S. Bauer, M. Jäjer, G. I. Stegeman, M. Ahlheim, M. Stähelin, B. Zysset, F. Lehr, M. Diemeer, and M. C. Flipse 


\section{Polymer waveguides with optimized overlap integral for modal dispersion phase- matching}

Cite as: Appl. Phys. Lett. 70, 3347 (1997); https://doi.org/10.1063/1.119166

Submitted: 17 February 1997 . Accepted: 23 April 1997 . Published Online: 04 June 1998

W. Wirges, S. Yilmaz, W. Brinker, S. Bauer-Gogonea, S. Bauer, M. Jäger, G. I. Stegeman, M. Ahlheim, M. Stähelin, B. Zysset, F. Lehr, M. Diemeer, and M. C. Flipse

\section{ARTICLES YOU MAY BE INTERESTED IN}

Fabrication and structural properties of AIN submicron periodic lateral polar structures and waveguides for UV-C applications

Applied Physics Letters 108, 261106 (2016); https://doi.org/10.1063/1.4955033

Second harmonic generation in phase matched aluminum nitride waveguides and micro-ring resonators

Applied Physics Letters 100, 223501 (2012); https://doi.org/10.1063/1.4722941

Second-harmonic generation through optimized modal phase matching in semiconductor waveguides

Applied Physics Letters 83, 620 (2003); https://doi.org/10.1063/1.1596726

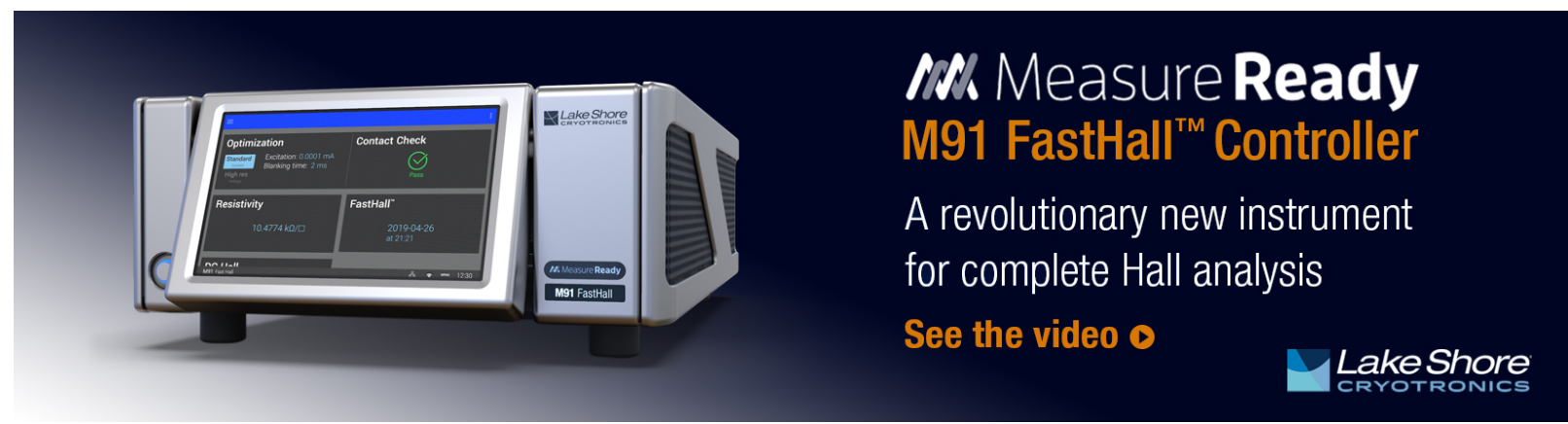




\title{
Polymer waveguides with optimized overlap integral for modal dispersion phase-matching
}

\author{
W. Wirges, S. Yilmaz, W. Brinker, S. Bauer-Gogonea, and S. Bauer ${ }^{\mathrm{a})}$ \\ Heinrich Hertz Institut für Nachrichtentechnik, D-10587 Berlin, Germany \\ M. Jäger and G. I. Stegeman \\ Center for Research and Education in Optics and Lasers, University of Central Florida, \\ Orlando, Florida 32816-2700
}

M. Ahlheim, M. Stähelin, B. Zysset, and F. Lehr

SANDOZ Optoelectronics, F-68330 Huningue, France

M. Diemeer and M. C. Flipse

AKZO Nobel Electronic Products, Arnhem, The Netherlands

(Received 17 February 1997; accepted for publication 23 April 1997)

\begin{abstract}
Modal dispersion phase-matched second harmonic generation is demonstrated in new poled polymer waveguide geometries with a nonlinear optical core consisting of two side-chain polymers with different glass transition temperatures. After poling above and between the respective glass transitions, the sign of the nonlinear optical coefficient is reversed in the two polymers, thereby improving the overlap integral. Conversion efficiencies up to $7 \% / \mathrm{W} \mathrm{cm}{ }^{2}$ were achieved in the first experiments. (C) 1997 American Institute of Physics. [S0003-6951(97)04925-5]
\end{abstract}

Second order nonlinear optical processes in the telecommunication windows at 1.3 and $1.55 \mu \mathrm{m}$ have regained attention recently for parametric amplification, wavelength conversion, and for cascading for all-optical switching, spatial solitons, etc. ${ }^{1}$ Cascading is possible via second-harmonic generation (SHG) and difference frequency generation (DFG) or by optical rectification (OR) and the electro-optic (EO) effect. ${ }^{1}$ Nonlinear optical (NLO) polymers seem to be very interesting materials for waveguide SHG due to their large nonresonant second order nonlinearities after poling. Efficient SHG requires phase matching (PM) so that the harmonic fields generated in different parts along the waveguide interfere constructively at the output. There are different ways to achieve PM, such as anomalous dispersion $\mathrm{PM},{ }^{2}$ quasi-phase-matching (QPM) ${ }^{3}$ and modal dispersion phasematching (MDPM). ${ }^{4}$ Anomalous dispersion PM suffers from limited transparency, while periodical poling for QPM leads to significant surface deformations and small values for the periodically modulated nonlinearity. ${ }^{5}$ Therefore MDPM seems to be an interesting alternative for efficient SHG.

Efficient modal dispersion phase-matching requires sophisticated multilayer fabrication techniques. Because of the usual waveguide and material dispersion with wavelength, the SH appears as a higher order guided mode. ${ }^{6}$ Because the $\mathrm{SH}$ field is rarely the final output for processes such as cascading, the resulting complicated field structure is not a limitation. However, it can lead to low conversion efficiencies $\left(\propto|S|^{2}\right)$ due to interference effects across the waveguide dimensions inherent in the overlap integral $S$ where:

$$
S=\sqrt{t} \int_{0}^{t} \chi_{33}^{(2)}(z)\left[E_{z}^{n, \omega}(z)\right]^{2} E_{z}^{m, 2 \omega}(z) d z .
$$

Here $t$ is the core thickness, $\chi_{33}^{(2)}(z)$ is the relevant spatially

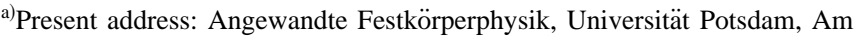
Neuen Palais 10, D-14469 Potsdam, Germany.

Electronic mail: sbauer@hhi.de
}

varying second order nonlinear optical susceptibility tensor element (for TM modes in our case), $E_{z}^{n, \omega}(z)$ and $E_{z}^{m, 2 \omega}(z)$ denote the $z$ component of the electric field of the fundamental and the second harmonic mode, respectively, and $m$ and $n$ (typically $n=0$ ) are the respective mode numbers. Because $E^{m, 2 \omega}(z)$ changes sign $m$ times across the waveguide, the integral is reduced unless (a) the sign of the nonlinearity is also reversed $m$ times or (b) the nonlinearity is zero whenever the field is negative (or positive). Figure 1 illustrates concept (a) by showing the calculated electric field distribution of the $\mathrm{TM}_{1}^{2 \omega}$ and $\mathrm{TM}_{2}^{2 \omega}$ modes (top left and right) and the required nonlinearity profile across the waveguide core for an optimized overlap integral $S$ for $\mathrm{TM}_{0}^{\omega} \rightarrow \mathrm{TM}_{1}^{2 \omega}$ (bottom left) and $\mathrm{TM}_{0}^{\omega} \rightarrow \mathrm{TM}_{2}^{2 \omega}$ (bottom right) mode conversion. The calculations are based on the refractive indices of the polymers described below. Both approaches (a) and (b) have been used for slab waveguides made from LangmuirBlodgett and polymer films. ${ }^{4,7-10}$ MDPM with

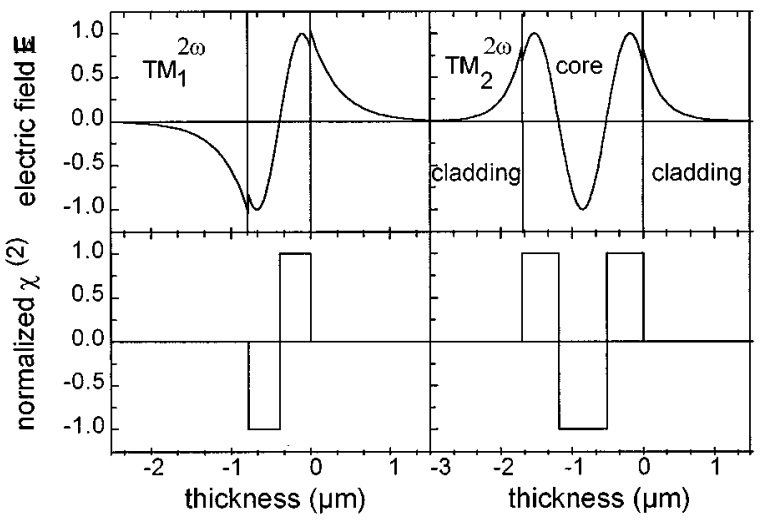

FIG. 1. Electric field distribution of the $\mathrm{TM}_{1}^{2 \omega}$ mode (top left) and the $\mathrm{TM}_{2}^{2 \omega}$ mode (top right). In order to obtain a large overlap integral, the nonlinearity must change sign once across the core thickness for $\mathrm{TM}_{0}^{\omega} \rightarrow \mathrm{TM}_{1}^{2 \omega}$ mode conversion (bottom left) and twice for $\mathrm{TM}_{0}^{\omega} \rightarrow \mathrm{TM}_{2}^{2 \omega}$ (bottom right). 


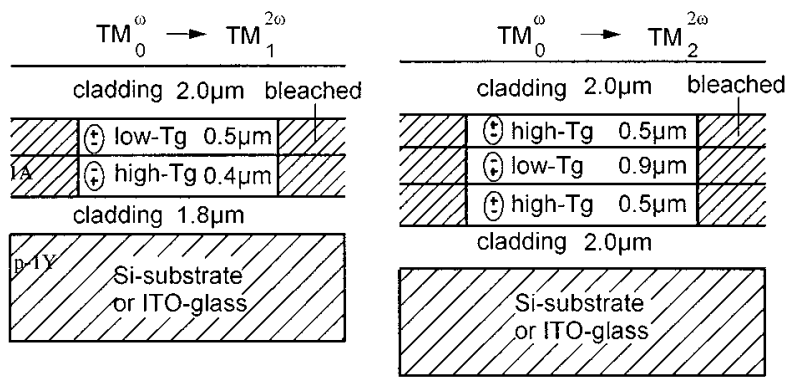

FIG. 2. Cross-section of polymer channel waveguides with optimized overlap integral for $\mathrm{TM}_{0}^{\omega} \rightarrow \mathrm{TM}_{1}^{2 \omega}$ and $\mathrm{TM}_{0}^{\omega} \rightarrow \mathrm{TM}_{2}^{2 \omega}$ PM SHG. The steplike dipole orientation profile indicated in the figure is obtained by consecutive thermally assisted poling above and between the respective glass transition temperatures. Channels of varying widths from 1 to $5 \mu \mathrm{m}$ were defined by photobleaching.

$\mathrm{TM}_{0}^{\omega} \rightarrow \mathrm{TM}_{1}^{2 \omega}$ was demonstrated in a slab and a channel multilayer waveguide with a guiding layer consisting of a passive and a nonlinear optically active polymer film ${ }^{4,7}$ and with $\mathrm{TM}_{0}^{\omega} \rightarrow \mathrm{TM}_{2}^{2 \omega}$ in a channel waveguide with a guiding layer consisting of a single nonlinear optically active layer. ${ }^{8}$ Channel waveguides are required for practical applications and a high conversion efficiency $\eta=P_{2 \omega} / P_{\omega}^{2} L^{2}$ $=1 \% / \mathrm{W} \mathrm{cm} \mathrm{cm}^{2}$ (with $P_{2 \omega}$ the power of the second harmonic light, $P_{\omega}$ the power of the fundamental light, and $L$ the device length) was achieved even in this latter nonoptimized case. ${ }^{8}$ For $\mathrm{TM}_{0}^{\omega} \rightarrow \mathrm{TM}_{1}^{2 \omega}$ mode conversion up to four times the efficiency may be expected by replacing the linear inactive region by a region of opposite nonlinearity $\left(\chi_{33}^{(2)}\right.$ coefficient). Such a steplike nonlinearity profile has been achieved in slab waveguides, for example, by using the LangmuirBlodgett technique. ${ }^{9,10}$ In this letter we demonstrate a technique for implementing sequentially inverted poled polymer layers in channel waveguides and preliminary measurements of SHG in them.

Our approach uses the waveguides schematically shown in Fig. 2. The core of the waveguide consists of two nonlinear optical side-chain polymers with different glass transition temperatures $T_{g 1}$ and $T_{g 2}$ with $T_{g 1}>T_{g 2}$. In order to obtain the desired change of sign of the nonlinear optical coefficient, steplike dipole orientation profiles, as indicated in Fig. 2 , are required. This is achieved by a two step poling technique, reported earlier in more detail. ${ }^{11}$ First the full structure is poled near the $T_{g 1}$ so that all of the polymer layers are poled in the same direction. The temperature is then reduced to near $T_{g 2}$ and the reversed poling field is again applied to the full structure. Although the orientation of the (low) $T_{g 2}$ material is reversed, the temperature is too low to repole the (high) $T_{g 1}$ material leading to the desired periodically reversed sequence of layers. Here we report on these new polymer based waveguide structures with optimized overlap integral for efficient $\mathrm{TM}_{0}^{\omega} \rightarrow \mathrm{TM}_{1}^{2 \omega}$ and $\mathrm{TM}_{0}^{\omega} \rightarrow \mathrm{TM}_{2}^{2 \omega}$ mode conversion.

For the experiments, waveguide structures were prepared by multilayer spin-coating of appropriate polymer solutions onto silicon or ITO-coated glass substrates. In order to separate the guided mode fields from the absorbing electrodes, the guiding layers were sandwiched between two buffer layers (PC polymer from AKZO). For the guiding

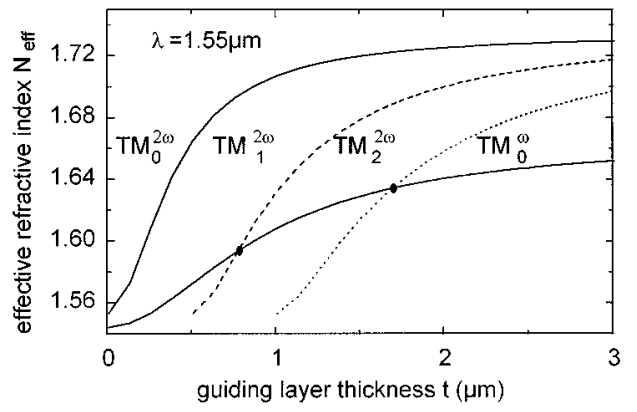

FIG. 3. Effective index $N_{\text {eff }}$ vs core thickness $t$ of a symmetrical slab waveguide for the lowest order transverse magnetic fundamental mode $\mathrm{TM}_{0}^{\omega}$ and for the first three modes at the second harmonic frequency. The phasematching conditions are fulfilled for $\mathrm{TM}_{0}^{\omega} \rightarrow \mathrm{TM}_{1}^{2 \omega}$ at a core thickness of 0.7 $\mu \mathrm{m}$ and for $\mathrm{TM}_{0}^{\omega} \rightarrow \mathrm{TM}_{2}^{2 \omega}$ at a core thickness of $1.7 \mu \mathrm{m}$.

layers, two different poly(styrene-maleic anhydride) copolymers with chemically attached Disperse Red 1 side groups (products 9511 and 9512 from SANDOZ ${ }^{12}$ ) and glass transitions $T_{g}=137$ and $164{ }^{\circ} \mathrm{C}$ were used. In order to prevent mixing of the side-chain polymers, the samples were baked for several hours at elevated temperatures after every spincoating step. In addition, the viscosity of the polymer solutions and the rotation speed during spin-coating were optimized.

Figure 3 shows that the PM condition can be fulfilled in this structure only for different fundamental and harmonic mode numbers. For $\mathrm{TM}_{0}^{\omega} \rightarrow \mathrm{TM}_{1}^{2 \omega}$ mode conversion, the guiding layer thickness (below $1 \mu \mathrm{m}$ ) is very near to the cut-off thickness. Better waveguiding is obtained for $\mathrm{TM}_{0}^{\omega} \rightarrow \mathrm{TM}_{2}^{2 \omega}$ mode conversion. The effective index of the transverse magnetic (TM) waveguide modes was calculated as a function of the total waveguide thickness $t$ for a wavelength $\lambda=1.55 \mu \mathrm{m}$ and with the refractive indices (as determined previously by prism coupling measurements) $n_{1}^{\omega}=1.664, n_{1}^{2 \omega}=1.725$ (core), $n_{2}^{\omega}=1.544$, and $n_{2}^{2 \omega}=1.553$ (cladding) of the polymers described below. Poling was performed with typical poling fields of $50 \mathrm{~V} / \mu \mathrm{m}$ at 165 and $140{ }^{\circ} \mathrm{C}$, respectively. No attempt was made in this initial study to optimize the poling conditions. Finally, channel waveguides with widths varying from 1 to $5 \mu \mathrm{m}$ were defined by photobleaching.

The optical nonlinearity achieved during the two-step poling process was monitored in situ by ellipsometrical EO measurements. ${ }^{13}$ The recording of the EO response, the SHG response with a fundamental at $1.064 \mu \mathrm{m}$, and the pyroelectric response upon linear heating of the polymer film verified the successful preparation of steplike dipole orientation profiles. $^{13}$

For the SHG experiments, 1-mm-long samples were diced for end-fire coupling. For such short waveguides, the measured waveguide losses of $4 \mathrm{~dB} / \mathrm{cm} @ 1.55 \mu \mathrm{m}$ were acceptable at the fundamental, but were high at the second harmonic wavelength (estimated to be larger than $50 \mathrm{~dB} / \mathrm{cm}$ @ $0.78 \mu \mathrm{m}$ ) due to the large residual absorption of the Disperse Red 1 chromophores. This limits the useful device length for SHG to only $L_{\max }=\ln [\alpha(2 \omega) / 2 \alpha(\omega)] /[\alpha(2 \omega)$ $-2 \alpha(\omega)]=1.8 \mathrm{~mm}$ with an assumed absorption of 50 $\mathrm{dB} / \mathrm{cm}$ at $0.78 \mu \mathrm{m} .{ }^{14}$ The first SHG experiments exhibited 
TABLE I. Comparison of SHG figures of merit $\eta$ and phase matching lengths $L_{\mathrm{PM}}$ for different mode conversion processes.

\begin{tabular}{|c|c|c|c|c|c|}
\hline $\begin{array}{c}\text { Mode } \\
\text { conversion }\end{array}$ & $\begin{array}{c}\text { NLO } \\
\text { chromophore }\end{array}$ & $\begin{array}{c}\text { Number } \\
\text { of } \\
\text { polymer } \\
\text { layers }\end{array}$ & $\begin{array}{c}\text { PM } \\
\text { wavelength } \\
\lambda_{\mathrm{PM}}(\mathrm{nm})\end{array}$ & $\begin{array}{c}\text { PM } \\
\text { distance } \\
L_{\mathrm{PM}}(\mathrm{mm})\end{array}$ & $\begin{array}{l}\text { Figure } \\
\text { of merit }\end{array}$ \\
\hline $\begin{array}{l}\mathrm{TM}_{0}^{\omega}-\mathrm{TM}_{0}^{2 \omega} \\
(\mathrm{QPM})^{\mathrm{a}}\end{array}$ & DANS & 3 & 1615 & 2 & $0.05 \% / \mathrm{W} \mathrm{cm} 2$ \\
\hline $\begin{array}{l}\mathrm{TM}_{0}^{\omega}-\mathrm{TM}_{2}^{2 \omega} \\
(\mathrm{PM})^{\mathrm{b}}\end{array}$ & DANS & 3 & 1535 & 2 & $1 \% / \mathrm{W} \mathrm{cm}{ }^{2}$ \\
\hline $\begin{array}{l}\mathrm{TM}_{0}^{\omega}-\mathrm{TM}_{1}^{2 \omega} \\
(\mathrm{PM})\end{array}$ & DR1 & 4 & 1610 & 2 & $3-4 \% / \mathrm{W} \mathrm{cm}$ \\
\hline $\begin{array}{l}\mathrm{TM}_{0}^{\omega}-\mathrm{TM}_{2}^{2 \omega} \\
(\mathrm{PM})\end{array}$ & DR1 & 5 & 1540 & 2 & $7 \% / \mathrm{W} \mathrm{cm}{ }^{2}$ \\
\hline
\end{tabular}

${ }^{\mathrm{a}}$ Data from Ref. 5.

${ }^{\mathrm{b}}$ Data from Ref. 8.

PM-SHG for both waveguide structures. Table I compares the SHG figures of merit and phase matching lengths for mode-matched conversion processes in polymer channel waveguides. We have found good agreement between the experimentally measured PM wavelength and the PM wavelength calculated from the thickness of the waveguide core (10\% deviation). This is rather surprising because the small differences in the refractive indices of the two nonlinear optical polymers as well as the poling-induced birefringence have been neglected in the calculation. It is noteworthy that the maximum conversion efficiency $\eta$ achieved (which is among the highest reported for poled polymers so far) is nearly two orders of magnitude larger than the QPM based $\mathrm{TM}_{0}^{\omega} \rightarrow \mathrm{TM}_{0}^{2 \omega}$ mode conversion SHG. Furthermore, our results compare very favorably with the published value for $\mathrm{LiNbO}_{3}$ of $\eta=27 \% / \mathrm{W} / \mathrm{cm}^{2} .{ }^{15}$ However, assuming that the values for the nonlinearity in optimized single layer waveguides can be achieved, the measured figures of merit are more than one order of magnitude smaller than predicted theoretically, leaving a great deal of scope for improvement. We suspect that the problem lies in nonoptimized cladding layers which do not allow a large voltage drop to occur across the nonlinear polymer stack. Furthermore, in order to increase the conversion efficiency and (most important) the useful device length for SHG, new nonlinear optical polymers with a larger nonresonant second order susceptibility and a lower absorption around $800 \mathrm{~nm}$ (compared to DANS and DR1) are required. ${ }^{14}$

To summarize, we have demonstrated modal dispersion PM-SHG by mode conversion in new polymer waveguide structures. A significant improvement in conversion efficiency has been achieved compared to QPM-SHG or modal dispersion PM with nonoptimized overlap integral. Still higher conversion efficiencies are possible with optimized waveguides under optimized poling conditions.

The research in the US was supported by the Air Force Office of Scientific Research and the National Science Foundation and in Germany by the Federal Minister of Research and Technology.

${ }^{1}$ G. I. Stegeman, D. J. Hagan, and L. Torner, J. Opt. Quantum Electron. 28, 1691 (1996).

${ }^{2}$ T. C. Kowalczyk, K. D. Singer, and P. A. Cahill, Opt. Lett. 20, 2273 (1995).

${ }^{3}$ G. Khanarian, R. A. Norwood, D. Haas, B. Feuer, and D. Karim, Appl. Phys. Lett. 57, 977 (1990).

${ }^{4}$ K. Clays, J. S. Schildkraut, and D. J. Williams, J. Opt. Soc. Am. B 11, 655 (1994).

${ }^{5}$ M. Jäger, G. I. Stegeman, W. Brinker, S. Yilmaz, S. Bauer, W. H. G. Horsthuis, and G. R. Möhlmann, Appl. Phys. Lett. 68, 1183 (1996).

${ }^{6} \mathrm{H}$. Ito and H. Inaba, Opt. Lett. 2, 139 (1978).

${ }^{7}$ M. Flörsheimer, M. Küpfer, Ch. Bosshard, H. Looser, and P. Günter, Adv. Mater. Commun. 4, 795 (1992).

${ }^{8}$ M. Jäger, G. I. Stegeman, G. R. Möhlmann, M. C. Flipse, and B. J. Diemeer, Electron. Lett. 32, 2009 (1996).

${ }^{9}$ M. Küpfer, M. Flörsheimer, Ch. Bosshard, and P. Günter, Electron. Lett. 29, 2033 (1993).

${ }^{10}$ T. L. Penner, H. R. Motschmann, N. J. Armstrong, M. C. Ezenyilimba, and D. J. Williams, Nature (London) 367, 49 (1994).

${ }^{11}$ S. Bauer-Gogonea, S. Bauer, W. Wirges, and R. Gerhard-Multhaupt, Ann. Phys. (Leipzig) 4, 355 (1995).

${ }^{12}$ M. Ahlheim and F. Lehr, Macromol. Chem. Phys. 195, 361 (1994).

${ }^{13}$ S. Yilmaz, W. Wirges, W. Brinker, S. Bauer-Gogonea, S. Bauer, M. Jäger, G. I. Stegeman, M. Ahlheim, M. Stähelin, B. Zysset, F. Lehr, M. Diemeer, and M. C. Flipse, Proc. SPIE 3006, 382 (1997).

${ }^{14}$ A. Otomo, M. Jäger, G. I. Stegeman, M. C. Flipse, and M. Diemeer, Appl. Phys. Lett. 69, 1991 (1996).

${ }^{15}$ M. L. Bortz, M. A. Arbore, and M. Fejer, Opt. Lett. 20, 49 (1995). 